\title{
Clinical Characteristics and Visual Rehabilitation in Keratoconus Patients Presented at a Tertiary Eye Care Institute in Uttar Pradesh (India)
}

\section{Jude Nnoruga $^{1 *}$, Mosaib Omaer ${ }^{2}$, Ashi Khurana ${ }^{3}$ and Lokesh Chauhan ${ }^{4}$}

${ }^{1}$ B.Sc Clinical Optometry, Department of Clinical Optometry and Visual Sciences, $C L$ Gupta Eye Institute, Moradabad, India

${ }^{2}$ M.Sc Clinical Optometry, Department of Clinical Optometry and Visual Sciences, CL Gupta Eye Institute, Moradabad, India

${ }^{3}$ MS Ophthalmology, Department of Cornea and Refractive Error, CL Gupta Eye

Institute, Moradabad, India

${ }^{4} \mathrm{MSc}$, Department of Clinical Research, CL Gupta Eye Institute, Moradabad, India

*Corresponding Author: Jude Nnoruga, B.Sc Clinical Optometry, Department of

Clinical Optometry and Visual Sciences, CL Gupta Eye Institute, Moradabad, India.
Received: February 21, 2020

Published: April 21, 2020

(C) All rights are reserved by AJude Nnoruga., et al.

\begin{abstract}
Purpose: To assess the clinical characteristics and visual rehabilitation in Keratoconus patients.

Methods: Medical records of consecutive patients diagnosed of Keratoconus presented at a tertiary eye care institute during September 2009 to December 2017 were reviewed retrospectively. Demographic details (age, gender, family history of Keratoconus, and occupation), history of contact lens use, history of consanguineous marriages, presenting best corrected visual acuity, refractive error, clinical signs based on slit lamp biomicroscopy and best corrected visual acuity after refractive correction, were noted.

Results: Of the 96 patients, 135 eyes of 72 (75\%) patients were included in the study. Mean age at the time of diagnosis was $20 \pm$ 6.7 years (8 to 40 years). $87 \%$ of them had presented bilaterally. $69.4 \%$ of them were students. Myopic astigmatism with a mean equivalent of -1.90DS and increased cylinder of -3.09DC was more prevalent. 54.1\% of patients were either in advance or severe stage of Keratoconus. Spectacles were prescribed for 82 (60.7\%) eyes, contact lens for 19 (14.1\%) eyes, corneal collagen crosslinking with Riboflavin was done in 28 (20.7\%) eyes, deep anterior lamellar keratoplasty in 4 (3\%) eyes and optical penetrating keratoplasty in $2(1.5 \%)$ eyes. There was significant improvement in BCVA from presentation in all patients.

Conclusion: Age of presentation was distributed equally between 8 to 40 years of age. Majority of the patients presented bilaterally with advance to severe form of Keratoconus, which was different from published studies, where patients had presented at mild to moderate stage.
\end{abstract}

Keywords: Keratoconus; Contact Lens; Visual rehabilitation; Pentacam; C3R; Uttar Pradesh

\section{Introduction}

Keratoconus $(\mathrm{KCN})$ is a non-inflammatory idiopathic ecstatic disease of the cornea. It is a multifactorial disease where progressive thinning and weakening of central or paracentral stroma leads to decrease of visual acuity [1-3]. Prevalence of KCN varies with different geographical region of the world. It also depends on patient characteristics and diagnostic criteria used. In India, the reported prevalence of KCN is $0.02 \%$ per 100,000 [4]. Jonas., et al. [5] reported prevalence of $\mathrm{KC}$ using cut-off central corneal curvature value of $\geq 48 \mathrm{D}$ was $2.3 \%$, using cut off value $\geq 49 \mathrm{D}$ was $0.6 \%$ and using a cut off of $\geq 50 \mathrm{D}$ was $0.1 \%$.Higher prevalence of KCN is reported from warmer countries as compared to countries having cooler climate [4-7].
KCN usually occurs bilaterally but asymmetry is common [8]. $\mathrm{KCN}$ has found to be associated with continuous eye rubbing. Most of the studies from India $[9,10]$ reported higher prevalence of KCN in males however, Jonas., et al. reported higher prevalence in females [4]. KCN presents at an younger age in India in comparison to western countries [9]. Vogt's striae, prominent corneal nerves, fleischer's ring are the signs of early to moderate KCN and, corneal scarring oil droplet sign, acute corneal hydrops, Rizzuti's sign and munson's sign are the late signs of KCN [11].

KCN is classified in different ways, in terms of shape of cone, severity level (based on keratometric readings), or its progression. In KCN, refractive correction is done by spectacle, and contact lens 
use. Corneal invasive procedure scan slow or stop the progression $\mathrm{KCN}$. Choice of treatment modality depends on patient characteristics, and severity of disease [12].

The epidemiology of the disease can help us to understand risk factors for a group of population and its timely management. This can help us to educate and counsel patient on the best available rehabilitation to achieve a good visual outcome.

\section{Aim of the Study}

This study aimed to assess the clinical characteristics and visual rehabilitation in KCN patients presented at cornea clinic of a tertiary eye care institute.

\section{Methods}

The study was approved by the institutional ethics committee. The study adhered to the principles of declaration of Helsinki. All medical record of consecutive patients with diagnosis of KCN reported to our cornea clinic over the period of September 2009 to December 2017 were retrospectively reviewed. Inclusion criteria were patients with diagnosis of $\mathrm{KCN}$ in either eye (unilateral or bilaterally) based on clinical and topography findings, with or without systemic abnormalities, with or without history of using contact lenses. Record of patient having corneal inflammations, corneal scarring, previous eye surgeries, patients diagnosed of KCN secondary to trauma, any other coexistence of ocular pathology other than KCN were excluded. Patients with insufficient data of corneal topographical evaluations were also excluded. In this study, KC was classified based on central cornea curvature value measured by keratometric $(\mathrm{K})$ readings as established by Buxton [13]. According to this criteria, keratometric reading of less than 45D in both meridians is mild KCN, between $45-52 \mathrm{D}$ in both Meridians is moderate $\mathrm{KCN},>52 \mathrm{D}$ in both meridians is advance $\mathrm{KCN}$ and $>62 \mathrm{D}$ in both meridians is severe KCN.

Demographic details (age, gender, family history, occupation, and with other associated ocular conditions), history of contact lens use, history of eye rubbing, history of consanguineous marriage, presenting best corrected visual acuity (BCVA), BCVA after refractive correction, refractive error, clinical signs based on slit lamp biomicroscopy were noted for every patient. The keratometry and pachymetry measurements obtained by Pentcam (Oculus Optikgeräte $\mathrm{GmbH}$, Wetzlar, Germany) topography were recorded. Spectacle correction, contact lens use, and other corneal invasive procedure performed were also noted.

\section{Statistical evaluation}

The statistical analysis was performed with SPSS 17.0 software
(SPSS Inc, Chicago, IL, USA). Descriptive statistics were obtained to determine the frequency and proportions. Mean and standard deviation was calculated for continuous variables. The alpha-type error was set to 0.05 . For statistical analysis, values of snellen visual acuity were converted to logMAR visual acuities. Chi square test, and independent $t$ test was used to compare identified variables between two groups. Analysis of variance (ANOVA) and posthoc analysis using Bonferroni method was conducted to compare the mean change in logMAR visual acuity among different groups (spectacles, contact lens, and C3R procedure).

\section{Results}

Ninety six patients with KC were reported at our institute during the study period. Of them $72(75 \%, \mathrm{n}=96)$ patients (135 eyes) had matched our inclusion criteria. Out of 24 patients whose records were excluded, $6(6.25 \%, \mathrm{n}=24)$ patients had history of head/ocular injury by cricket ball, bat stick. One patient had ocular injury with fevi-quick glue (cyanoacrylate).

Out of 72 patients, 37 [51.4\%; 95\% CI: 39.3 - 63.3\%] were male and 35 [48.6\%; 95\% CI: 36.7 - 60.7\%] were female. 63 [87.5\%; 95\% CI: 77.6 - 94.1\%] patients were with bilateral KCN and the rest 9 [12.5\%; 95\% CI: 5.9 - 22.4\%] were unilateral. No patient had history of using contact lens. History of consanguineous marriage was not present in any patient. The mean age at the time of diagnosis of KCN was $20 \pm 6.7$ (range: $8-40$ ) years. Three $(4.2 \%, n=72$ ) were below 10 years of age, $16(22.3 \%, n=72)$ were between $10-15$ years, $18(25 \%, n=72)$ were between $16-20$ years, $23(31.9 \%, n=$ 72) were between 21 - 25 years, and rest $23(16.7 \%, n=72)$ were more than 25 years of age. The mean age of male patients was 19.5 \pm 5.6 years and of females was $20.6 \pm 7.7$ years $(p=0.48$, independent $t$ test). The Percentage of patient's occupation was highest in students $(n=50) 69.4 \%$ and lowest in farmer, government service and, automobile driver all with a frequency of $(n=1) 1.4 \%$ each.

Mean maximum keratometry ( $\mathrm{K}$ max) reading was $56.4 \pm 10.5 \mathrm{D}$ and mean central corneal thickness (CCT) was $462.7 \pm 66.9 \mathrm{~mm}$. Mean $\mathrm{K}$ max reading in male patients was $55.5 \pm 9.7 \mathrm{D}$, and in females was $57.8 \pm 11.4 \mathrm{D}$ ( $\mathrm{p}=0.21$, independent t test). Mean CCT in male patient was $460.1 \pm 58.2 \mathrm{~mm}$ and in females were $463.4 \pm 76$ $\mathrm{mm}(\mathrm{p}=0.77$, independent $\mathrm{t}$ test). 15 (11.1\%) patients were with mild KCN, 47 (34.8\%) with moderate KCN, 43 (31.9\%) were with advanced KCN and 30 (22.2\%) of them were with severe KCN. Cumulative percentage of advance and severe form of $\mathrm{KCN}$ was $54.1 \%$. In mild KCN, the mean sphere and cylinder was $-1.5 \mathrm{D}$ and $-1.75 \mathrm{D}$, in moderate was $-0.62 \mathrm{D}$ and $-2.22 \mathrm{D}$, in advanced was $-2.11 \mathrm{D}$ and $-4.18 \mathrm{D}$ and in severe was $-3.93 \mathrm{D}$ and $-2.94 \mathrm{D}$. The mean spherical equivalent was $-3.45 \mathrm{D}$ in all grades of Keratoconus. 
The proportion of eyes with scissor's reflex, Fleischer's ring and prominent corneal nerves was $45.9 \%(\mathrm{~N}=62), 40.7 \%(\mathrm{~N}=55)$ and $38.5 \%(\mathrm{~N}=52)$ respectively. Proportion of Rizuti sign and Oil drop sign was $1.5 \%(\mathrm{~N}=2)$ and $2.2 \%(\mathrm{~N}=3)$ respectively. The distribution of signs was shown in table 1.

\begin{tabular}{|l|c|c|c|}
\hline S. No & SIGNS & Present & \% \\
\hline 1 & Scissor Reflex & 62 & $45.9 \%$ \\
\hline 2 & Prominent corneal nerves & 52 & $38.5 \%$ \\
\hline 3 & Vogt striae & 28 & $20.7 \%$ \\
\hline 4 & Fleischer ring & 55 & $40.7 \%$ \\
\hline 5 & Corneal scarring & 21 & $15.6 \%$ \\
\hline 6 & Munson sign & 33 & $24.4 \%$ \\
\hline 7 & Rizuti sign & 2 & $1.5 \%$ \\
\hline 8 & Acute corneal hydrops & 4 & $3.0 \%$ \\
\hline 9 & Oil drop sign & 3 & $2.2 \%$ \\
\hline
\end{tabular}

Table 1: Distribution of signs of KCN (135 Eyes).

For refractive correction, spectacles were dispensed to 82 [60.7\%; 95\% CI: 52 - 69\%] eyes, and contact lenses were dispensed to 19 [14.1\%; 95\% CI: 8.7 - 21.1\%] eyes. Corneal collagen crosslinking with riboflavin (C3R) was done in 28 [20.7\%; 95\% CI: 14.2 - 28.6\%] eyes, deep anterior lamellar keratoplasty (DALK) in 4 [3\%; 95\% CI: $0.8-7.4 \%$ ] eyes, and optical penetrating keratoplasty (OPK) in 2 [1.5\%; 95\% CI: 0.2 - 5.2\%] eyes.

All eyes $(n=4)$ that underwent corneal grafting were in the severe stage of KCN, out of 28 eyes that underwent C3R procedure, $10(35.7 \%)$ were in advanced stage the remaining 8 (28.5\%), 6 $(21.4 \%)$ and $4(14.2 \%)$ eyes were in moderate, severe and mild stages respectively. Out of 19 eyes managed with contact lens, 9 (47.3\%) eyes were in advanced stage, 7 (36.8\%) eyes in severe stage and the rest were $1(5.2 \%)$ and $2(10.5 \%)$ eyes in mild and moderate stages respectively (Table 2 ).

After C3R procedure $(\mathrm{n}=28)$, spectacles were dispensed to 20 (71.4\%) eyes, and contact lens in 8 (28.5\%) eyes. After OPK, (2 eyes) glasses were dispensed to 2 eyes, and after DALK ( 4 eyes) glasses were dispensed to 2 eyes and contact lens in 2 eye. There was statistically significant improvement of BCVA after refractive correction. Table 3 shows the cross tabulated comparison between BCVA at presentation and BCVA after refractive correction.

The mean improvement in visual acuity was $-0.52 \log M A R$ with spectacle, $-0.71 \log$ MAR with C3R surgery, and $-0.81 \log$ MAR with contact lenses (one way ANOVA, $\mathrm{p}=0.02$ ) (Table 4).

\begin{tabular}{|l|c|c|c|c|c|c|c|}
\hline & \multicolumn{7}{|c|}{ Mode of Refractive Error correction } \\
\cline { 2 - 8 } & Spectacles & Contact Lens & C3R & OPK & DALK & Total \\
\cline { 2 - 8 } & & RGP & ROSK K & & & & \\
\hline Mild KCN & 9 & 2 & 0 & 4 & 0 & 0 & 15 \\
\hline $\begin{array}{l}\text { Moderate } \\
\text { KCN }\end{array}$ & 38 & 1 & 0 & 8 & 0 & 0 & 47 \\
\hline $\begin{array}{l}\text { Advance } \\
\text { KCN }\end{array}$ & 24 & 7 & 2 & 10 & 0 & 0 & 43 \\
\hline $\begin{array}{l}\text { Severe } \\
\text { KCN }\end{array}$ & 11 & 5 & 2 & 6 & 2 & 4 & 30 \\
\hline Total & 82 & 15 & 4 & 28 & 2 & 4 & 135 \\
\hline
\end{tabular}

Table 2: Treatment distribution among different grades of KC.

\section{Discussion}

In this study, significant predominance in gender distribution was not reported which is similar to collaborative longitudinal evaluation of keratoconus (CLEK) Study [55.9\% male, 44.1\% female] [14], by a studies done in Palestine [49.5\% were males, $50.5 \%$ were females] [15] and India [48\% were males, 52\% were females] [16]. However in a study by Fatima., et al. from India [9], $63 \%$ of patient population were males and $37 \%$ were females. The average age at presentation in this study was consistent with previous reports from India [9,16] (24 years and $20.2 \pm 6.4$ years), Malaysia [17] (20.9 \pm 5.6 years) and Palestine [15] (23.4 \pm 7.4 years). The mean age was slightly lower in an study conducted in Saudi Arabia [6]. Majority of the patients were students ( $n=50 ; 69.4 \%$ ) which correlates with the age group of adulthood. The lowest population was seen in farmers, government service, and drivers all at a percentage of $1 \%$ respectively.

This study reported the onset of KCN at an early age, which is consistent with previous studies $[9,16,17]$. The early onset of KC are associated with several factors which include chronic eye rubbing, genetics [18,19] environmental and geographical factors such as consanguineous marriage and ultraviolet exposures [6]. However in this study, only 1 out of 72 patient reported a family history of KCN by his father, and no report of marriage consanguinity. Higher incidence of KCN was reported from countries that have a hot, dry and dusty tropical or sub-tropical climates. It is therefore evident that aetiology of KCN could be multifactorial.

There was no statistically significant difference of mean steepest keratometry readings between male and female. This was similar to a previously reported study from Malaysia study where it was $54.68 \pm 7.09 \mathrm{D}$ in males and $53.51 \pm 6.39 \mathrm{D}$ in females [17] 


\begin{tabular}{|c|c|c|c|c|c|c|c|c|c|c|c|c|}
\hline \multirow{2}{*}{ BCVA at Presentation } & \multicolumn{12}{|c|}{ BCVA after refractive correction } \\
\hline & & $20 / 20$ & $20 / 25$ & $20 / 30$ & $20 / 40$ & $20 / 50$ & $20 / 60$ & $20 / 80$ & $20 / 100$ & $20 / 120$ & $20 / 400$ & Total \\
\hline & $20 / 20$ & 4 & 0 & 0 & 0 & 0 & 0 & 0 & 0 & 0 & 0 & 4 \\
\hline & $20 / 25$ & 6 & 1 & 0 & 0 & 0 & 0 & 0 & 0 & 0 & 0 & 7 \\
\hline & $20 / 30$ & 5 & 1 & 0 & 2 & 0 & 0 & 0 & 0 & 0 & 0 & 8 \\
\hline & $20 / 40$ & 8 & 2 & 1 & 1 & 0 & 0 & 0 & 0 & 0 & 0 & 12 \\
\hline & $20 / 50$ & 6 & 1 & 0 & 0 & 0 & 0 & 0 & 0 & 0 & 0 & 7 \\
\hline & $20 / 60$ & 7 & 3 & 0 & 1 & 0 & 0 & 0 & 0 & 0 & 0 & 11 \\
\hline & $20 / 80$ & 2 & 3 & 2 & 3 & 0 & 1 & 2 & 1 & 0 & 0 & 14 \\
\hline & $20 / 100$ & 4 & 3 & 3 & 1 & 0 & 1 & 2 & 0 & 0 & 0 & 14 \\
\hline & $20 / 120$ & 0 & 1 & 0 & 2 & 0 & 0 & 0 & 0 & 0 & 0 & 3 \\
\hline & $20 / 125$ & 0 & 1 & 0 & 0 & 0 & 0 & 0 & 0 & 0 & 0 & 1 \\
\hline & $20 / 160$ & 4 & 3 & 0 & 0 & 0 & 0 & 0 & 0 & 0 & 0 & 7 \\
\hline & $20 / 200$ & 2 & 0 & 4 & 1 & 2 & 1 & 0 & 1 & 0 & 0 & 11 \\
\hline & $20 / 250$ & 0 & 0 & 1 & 0 & 0 & 0 & 0 & 0 & 0 & 0 & 1 \\
\hline & $20 / 400$ & 0 & 0 & 2 & 0 & 0 & 4 & 0 & 2 & 1 & 0 & 9 \\
\hline & $20 / 500$ & 0 & 0 & 0 & 1 & 0 & 1 & 0 & 0 & 0 & 0 & 2 \\
\hline & $20 / 600$ & 0 & 0 & 0 & 2 & 0 & 0 & 0 & 0 & 0 & 0 & 2 \\
\hline & $20 / 630$ & 1 & 1 & 0 & 0 & 0 & 0 & 0 & 0 & 0 & 1 & 3 \\
\hline & $20 / 800$ & 0 & 3 & 0 & 0 & 0 & 0 & 1 & 0 & 0 & 0 & 4 \\
\hline & $\mathrm{CF}$ & 2 & 2 & 1 & 3 & 0 & 5 & 1 & 0 & 0 & 1 & 15 \\
\hline & Total & 51 & 25 & 14 & 17 & 2 & 13 & 6 & 4 & 1 & 2 & 135 \\
\hline
\end{tabular}

Table 3: Comparison of BCVA (Cross tabulation).

\begin{tabular}{|c|c|c|c|c|c|c|}
\hline & \multirow[t]{2}{*}{$\mathbf{N}$} & \multirow[t]{2}{*}{ Mean } & \multirow[t]{2}{*}{ Std. Deviation } & \multicolumn{3}{|c|}{ 95\% Confidence Interval for Mean } \\
\hline & & & & Lower Bound & \multicolumn{2}{|c|}{ Upper Bound } \\
\hline Spectacles & 82 & -0.52 & 0.35 & -0.59 & \multicolumn{2}{|c|}{-0.44} \\
\hline C3R & 28 & -0.71 & 0.59 & -0.94 & \multicolumn{2}{|c|}{-0.47} \\
\hline Contact lens & 19 & -0.81 & 0.66 & -1.13 & \multicolumn{2}{|c|}{-0.47} \\
\hline Total & 127 & -0.60 & 0.47 & -0.68 & \multicolumn{2}{|c|}{-0.51} \\
\hline \multicolumn{7}{|l|}{ ANOVA } \\
\hline & & Sum of Squares & df & Mean Square & $\mathbf{F}$ & Sig. \\
\hline \multicolumn{2}{|l|}{ Between Groups } & 1.587 & 2 & 0.794 & 3.672 & 0.028 \\
\hline \multicolumn{2}{|l|}{ Within Groups } & 26.80 & 124 & 0.216 & & \\
\hline \multicolumn{2}{|l|}{ Total } & 28.39 & 126 & & & \\
\hline \multicolumn{7}{|c|}{ BCVA-CHANGE Bonferroni } \\
\hline \multirow{2}{*}{\multicolumn{2}{|c|}{ Categories }} & \multirow{2}{*}{$\begin{array}{c}\text { Mean Difference } \\
\text { (I-J) }\end{array}$} & \multirow[t]{2}{*}{ Std. Error } & \multirow[t]{2}{*}{ Sig. } & \multicolumn{2}{|c|}{ 95\% Confidence Interval } \\
\hline & & & & & Lower Bound & Upper Bound \\
\hline \multirow[t]{2}{*}{ Spectacles } & C3R & 0.19 & 0.1 & 0.22 & -0.06 & 0.44 \\
\hline & Contact lens & 0.28 & 0.12 & 0.06 & -0.01 & 0.58 \\
\hline \multirow[t]{2}{*}{ C3R } & Spectacles & -0.19 & 0.1 & 0.22 & -0.44 & 0.06 \\
\hline & Contact lens & 0.1 & 0.14 & 1 & -0.25 & 0.44 \\
\hline \multirow[t]{2}{*}{ Contact lens } & Spectacles & -0.28 & 0.12 & 0.06 & -0.58 & 0.01 \\
\hline & C3R & -0.1 & 0.14 & 1 & -0.44 & 0.25 \\
\hline
\end{tabular}

Table 4: Comparison of BCVA improvement after spectacles, contact lens, and C3R. 
In this study, moderate KCN was more prevalent (34.8\%), followed by advanced KCN in $31.9 \%$ and severe KCN in $22.2 \%$. More than $50 \%$ patient were in advance to severe form of KCN. In previous studies from Malaysia $7.6 \%$ in mild form, 30.1\% in moderate form, $4.4 \%$ in advanced form, $27.8 \%$ in severe form [17] and in Saudi Arabia it was found that $39.2 \%$ in early stage, $42.5 \%$ in moderate stage and $18.3 \%$ in advanced [5].

In other reported studies patient had a mild to moderate form of the disease at the time of diagnosis which was different from findings of this study where patients presented with an advance to severe form $[5,17]$. This could be because of late presentation of KCN patient, as $48.6 \%$ patient in this study belong to more than 20 years of age. This highlight the poor eye care seeking behaviour of population living in study area. The study area belong to sub-urban and rural area, and unavailability of nearby eye care services could be one factor associated with late presentation. Accidental discovery during routine eye examination and increasing trends towards refractive surgeries in myopic patients raises the likelihood of KCN discovery in moderate to advanced stage, as pre-operative assessment of keratometry by Pentacam (Oculus Optikgeräte GmbH, Wetzlar, Germany) is mandatory for all patients before these surgeries.

The mean spherical equivalent reported in this study was slightly less compared to the study done in Malaysia which was -6.25DS [17]. The proportion of eyes showing biomicroscopic findings showed corneal nerves and Fleischer's ring at 38.5\% and $40.7 \%$ respectively, similarly Saini., et al. [16] among Asian population reported frequency of Vogt's striae and Fleischer's ring was 50.8\% and 50\% respectively. Zadnik., et al. [14] had observed either Fleischer's ring or Vogt's striae in $68 \%$ of the eye. Weed., et al. [8] reported Fleischer's ring in $76 \%$ of the patients. Fleischer's ring, Vogt's striae or cornea scarring were the most frequently observed sign of KCN.

At presentation, $63.7 \%$ of patient had $20 / 80$ or lesser and after refractive correction BCVA was improved to 20/35 or better in $66.7 \%$ patients. Reduced visual acuity due to KCN was initially managed with spectacles. When spectacles fail to adequately correct visual acuity, contact lenses were the next option. Spectacles were dispensed to $60.7 \%$ of the KCN patients, which describes that the percentage of spectacle users is high for refractive correction in study area. Contact lenses were dispensed to $14.1 \%$ patients. Low dispensing of contact lenses were due to affordability, and accessibility of contact lenses services in study area. Most of the patients who were prescribed contact lenses, opted for spectacles due to low cost compared to contact lenses. Low dispensing of contact lens clearly indicating that more awareness needs to be made on best attainable mode of refractive correction for KCN patients.

4.5\% had corneal grafting (DALK and OPK) which was quite less compared to previous studies. Previous studies have reported that $10-25 \%$ of KCN patients ultimately require surgery [20,21]. All eye that underwent corneal grafting were in severe stage of KCN. Of the 34 eyes that underwent corneal invasive procedures to stop the progression of KCN, 25 eyes (74\%) had opted for glasses and the remaining 9 eyes (26\%) used contact lens.

\section{Conclusion}

In conclusion, only $4.5 \%$ of patients in this study require corneal surgery, which is significantly low from previous reports that $10-25 \%$ of KCN patients ultimately require surgery. Nearly $50 \%$ patient belong to more than 20 years of age. More than $50 \%$ patients were in advance to severe grade of KCN. Contact lens was dispensed to only $14 \%$ of patients. Patients vision was significantly improved by all method of refractive correction. Visual improvement from contact lens was the most.

\section{Bibliography}

1. Chang HY and Chodosh J. "The genetics of keratoconus". Seminars in Ophthalmology 28 (2013): 275-80.

2. Klintworth GK and Damms T. "Corneal dystrophies and keratoconus”. Current Opinion in Ophthalmology 6 (1995): 44-56.

3. Andreassen TT., et al. "Biomechanical properties of keratoconus and normal corneas". Experimental Eye Research 31.4 (1980): 435-441.

4. Jonas JB., et al. "Prevalence of keratoconus in rural Maharashtra in Central India: The Central India Eye and Medical Study". American Journal of Ophthalmology 148 (2009): 760-765.

5. Assiri AA., et al. "Incidence and severity of keratoconus in Asir province, Saudi Arabia”. British Journal of Ophthalmology 89 (2005): 1403-1406.

6. Ihalainen A. "Clinical and epidemiological features of keratoconus genetic and external factors in the pathogenesis of the disease". Acta Ophthalmologica 178 (1986): 1-64.

7. Nielsen K., et al. "Incidence and prevalence of keratoconus in Denmark". Acta Ophthalmologica Scandinavica 85.8 (2007): 890-892.

8. Weed KH., et al. "The Dundee University Scottish Keratoconus study: Demographics, corneal signs, associated diseases, and eye rubbing". Eye 22 (2008): 534-541. 
9. Fatima T., et al. "Demographic profile and visual rehabilitation of patients with keratoconus attending contact lens clinic at a tertiary eye care centre". Contact Lens and Anterior Eye 33 (2010): 19-22.

10. Sharma R., et al. "Clinical profile and risk factors for keratoplasty and development of hydrops in north Indian patients with keratoconus". Cornea 28.4 (2009): 367-370.

11. Keratoconus (2018).

12. Krachmer JH., et al. "Keratoconus and related noninflammatory corneal thinning disorders". Survey of Ophthalmology 28.4 (1984): 293-322.

13. Buxton JN. "Contact lenses in keratoconus". Contact and Intraocular Lens Medical Journal 4 (1978): 74-85.

14. Zadnik K., et al. "Corneal scarring and vision in keratoconus: a baseline report from the Collaborative Longitudinal Evaluation of Keratoconus (CLEK) Study". Cornea 19 (2000): 804812.

15. Shanti Y., et al. "Characteristics of keratoconic patients at two main eye centres in Palestine: a cross-sectional study". BMC Ophthalmology 18.1 (2018): 95.

16. Saini JS., et al. "Keratoconus in Asian eyes at a tertiary eye care facility". Clinical and Experimental Optometry 87.2 (2004): 97101.

17. Mohd-Ali B., et al. "Clinical characteristics of keratoconus patients in Malaysia: A review from a cornea specialist center". Journal of Optometry 5 (2012): 38-42.

18. Karimian F., et al. "Topographic evaluation of relatives of patients with keratoconus". Cornea 27 (2008): 874-878.

19. Kaya V., et al. "Evaluation of corneal topography with Orbscan II in first-degree relatives of patients with keratoconus". Cornea 27 (2008): 531-534.

20. Crews MJ., et al. "The clinical management of keratoconus: a 6 year retrospective study”. CLAO Journal 20 (1994): 194-197.

21. Kennedy RH., et al. "A 48-year clinical and epidemiological study of keratoconus". American Journal of Ophthalmology 101 (1986): 267-273.

\section{Assets from publication with us}

- Prompt Acknowledgement after receiving the article

- Thorough Double blinded peer review

- Rapid Publication

- Issue of Publication Certificate

- High visibility of your Published work

Website: www.actascientific.com/

Submit Article: www.actascientific.com/submission.php

Email us: editor@actascientific.com

Contact us: +919182824667 